\title{
Characterisation of an enterotoxin-negative, cytotoxin-positive strain of Clostridium sordellii
}

\author{
G. A. GREEN, V. SCHUÉ, R. GIRARDOT and H. MONTEIL \\ Laboratoire de Toxinologie Bactérienne, Laboratoire de Bactériologie de la Faculté de Médecine, Université \\ Louis Pasteur, 3 rue de Koeberlé, 67000 Strasbourg, France
}

\begin{abstract}
In ileal loop assay, ELISA and anion-exchange column chromatography, Clostridium sordellii strain 6018 was shown to produce a cytotoxin, but no detectable enterotoxin. DNA sequence and polymerase chain reaction analyses indicated that the lack of enterotoxin activity is not due to a lack of gene transcription, but to lack of a major portion of the enterotoxin gene. This is the first characterisation of such a strain.
\end{abstract}

\section{Introduction}

Clostridium sordellii causes gas gangrene in man, cattle and sheep [1-3]. This gram-positive anaerobic bacterium produces a haemorrhagic enterotoxin $(\mathrm{H})$ and a lethal cytotoxin (L), which have been purified, characterised and shown to be immunologically similar to C. difficile enterotoxin A and cytotoxin $\mathrm{B}$, respectively [4-7]. On the genome of $C$. difficile the cytotoxin gene is separated from the enterotoxin gene by a short open reading frame (ORF) which is flanked by short intergenic regions. It was originally thought that nontoxigenic strains of $C$. difficile lack the genes for both enterotoxin and cytotoxin [8-11], but in more recent studies a $C$. difficile strain that produces a modified cytotoxin and lacks the entire $3^{\prime}$ portion of the enterotoxin gene and part of the $5^{\prime}$ portion has been found [12-14]. Furthermore, $C$. difficile strains of serogroup $F$ possess cytotoxin and entrotoxin genes, but do not produce an enterotoxin and produce a modified cytotoxin [15].

C. sordellii has received less attention. Martinez and Wilkins [7] and Popoff [6] showed that $C$. sordellii strains VPI 9084 and IP 82 produce a cytotoxin and an enterotoxin, and we have studied $C$. sordellii 6018 cytotoxin $[4,5,16]$ and its gene [17]. This study examined the failure of $C$. sordellii strain 6018 to produce an enterotoxin and the absence of a major part, or possibly all, of the enterotoxin gene.

\section{Materials and methods}

\section{Bacterial strains and growth}

C. difficile 68750 and C. sordellii 6018 are clinical isolates from this clinical laboratory, and $C$. sordellii VPI 9048 was included as a toxin-positive control. Cultures were grown anaerobically at $37^{\circ} \mathrm{C}$ in BrainHeart Infusion Broth (Difco) for $72 \mathrm{~h}$ for protein studies and for $24 \mathrm{~h}$ for DNA analyses.

\section{Enterotoxin and cytotoxin assays}

Cell-free supernates from clostridial cultures were obtained by centrifugation $(5000 \mathrm{~g}, 5 \mathrm{~min})$ and filtration through a $0.45 \mu \mathrm{m}$ membrane filter. One $\mathrm{ml}$ was injected into the ileal loop of an anaesthetised rabbit. Fluid accumulation was measured $18 \mathrm{~h}$ later. Positive (Escherichia coli LT EWD 299, kindly supplied by Dr S. Falkow) and negative (phosphate-buffered saline) controls were included [18]. Enterotoxin was also assayed with the ToxA ELISA test (Biowhittaker, France) [19]. Cytotoxin assays were performed on McCoy cells cultured at $37^{\circ} \mathrm{C}$ in a humidified atmosphere of $\mathrm{CO}_{2} 5 \%$, air $95 \%$ [19].

\section{Chromatography}

Proteins from a further $500 \mathrm{ml}$ of the cell-free supernate were separated by anion-exchange chromatography on a MonoQ HR column, with $0-1 \mathrm{M} \mathrm{NaCl}$ gradient elution [4]. Fractions were assayed for cytotoxin activity. Cytotoxin-positive fractions were re-chromatographed and re-tested for cytotoxicity.

\section{DNA extraction and PCR analysis}

DNA was isolated from $5 \mathrm{ml}$ of culture [20] and $50 \mathrm{ng}$ were amplified in a total volume of $100 \mu \mathrm{l}$ [10]. Primers developed for the $C$. difficile enterotoxin gene [10] 


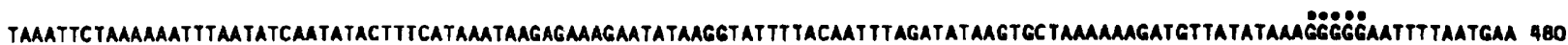

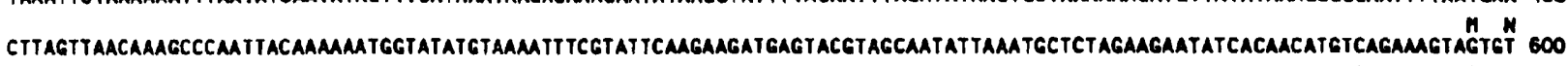
AGT'TGMANKG KA O

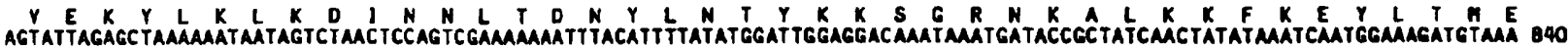

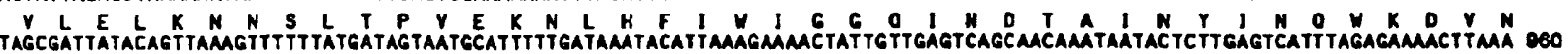

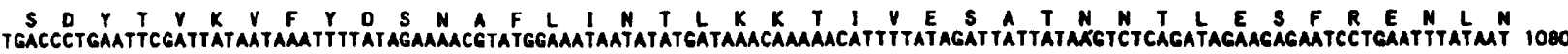

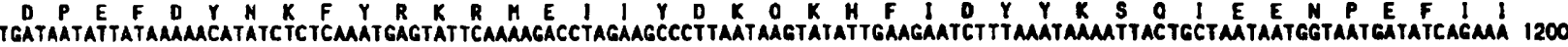

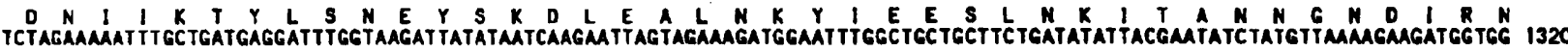

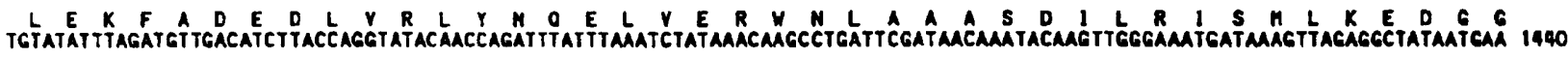
atÁTAAGgÁ D D Y D D

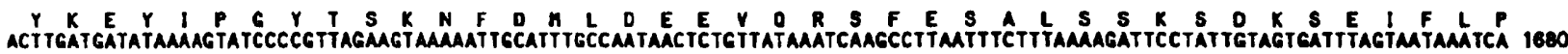

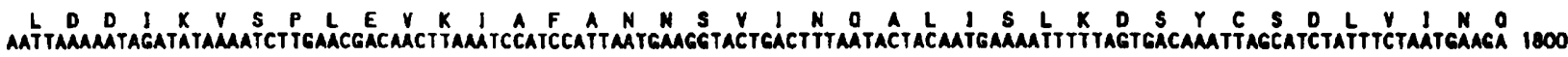
TAMTAT́ A

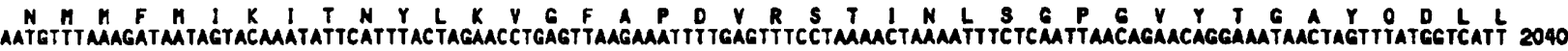

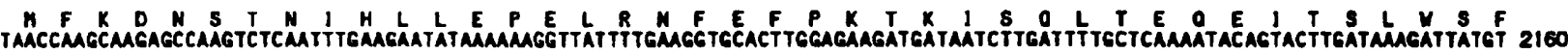

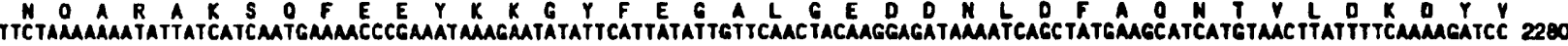
$S$
$S$
$K$

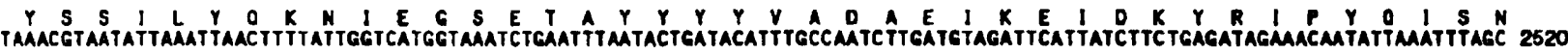

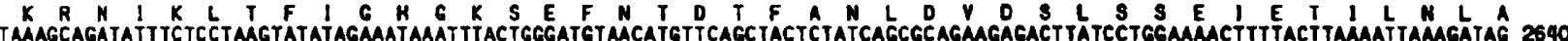

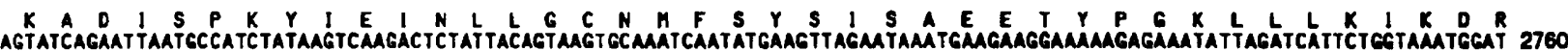
Y S E L P S

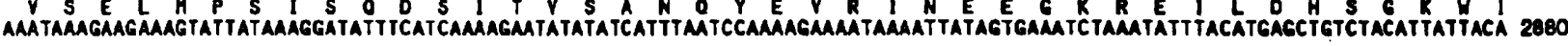

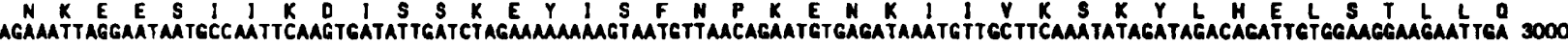

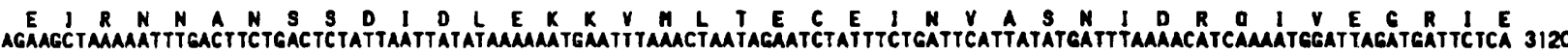

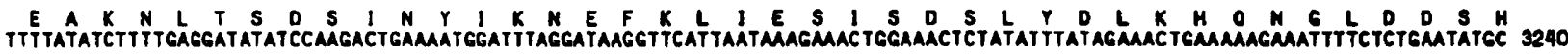

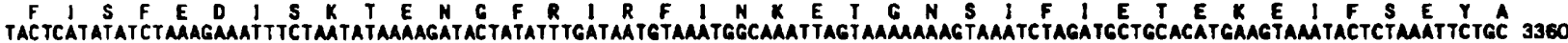

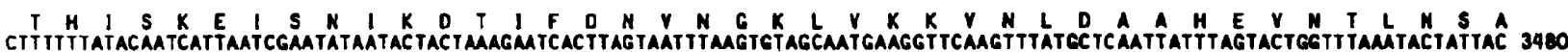

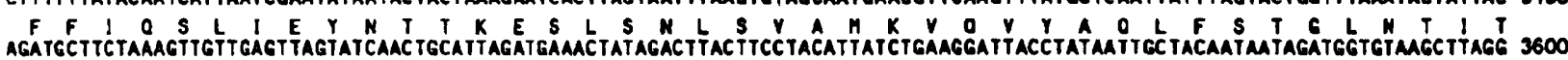

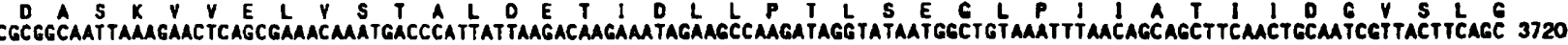

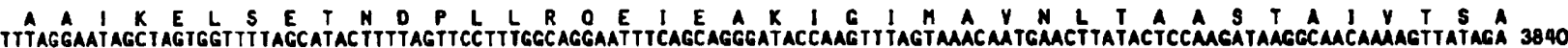

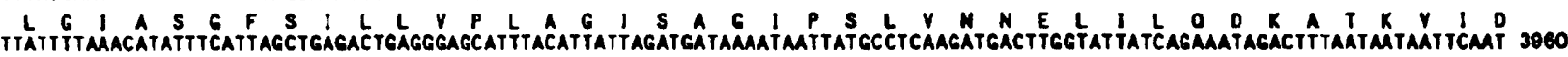

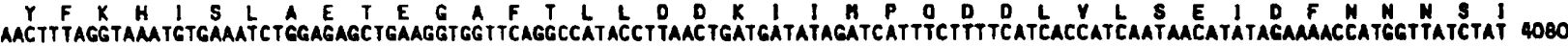

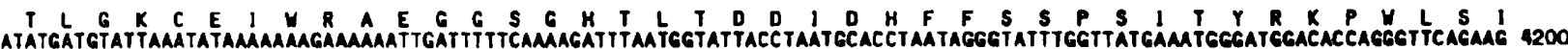

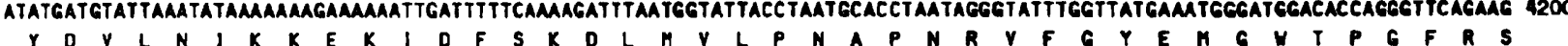

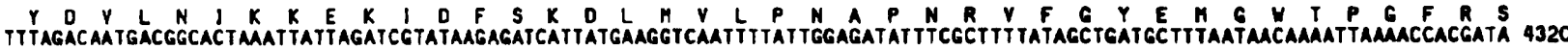

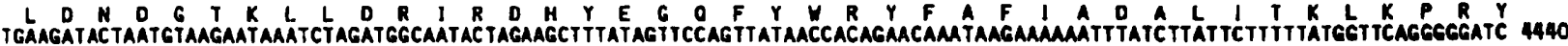

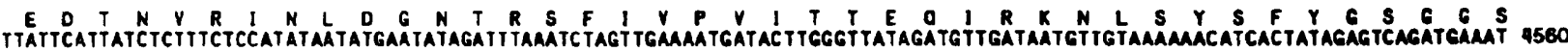

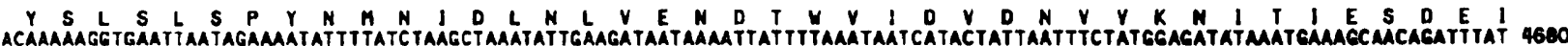

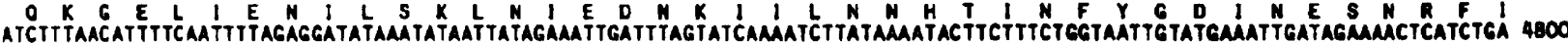

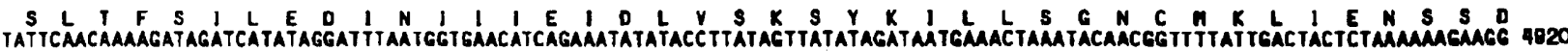

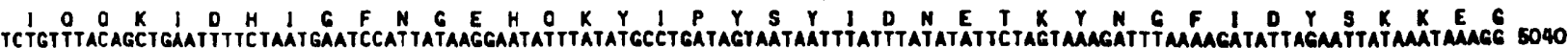

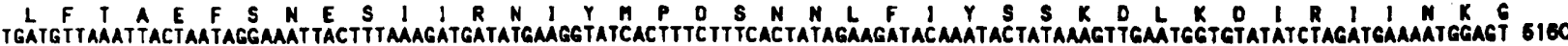

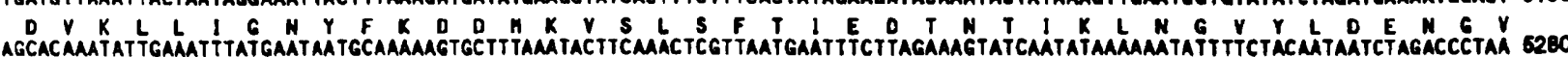
AGCACAAATAT TGAAATTTATGAATAATGCAAÁAGTGCTTTAMATACTICMACTCGTTAATGAATTTCTTAGAAAGTATCAATATAAAAAMATATTTTCTACMATAATCTAGACCCTAA

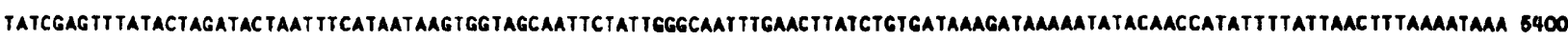

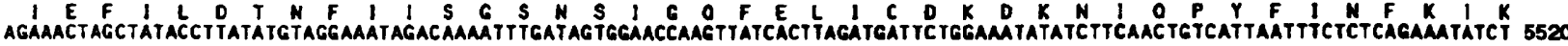

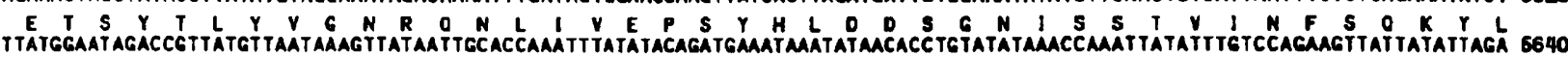

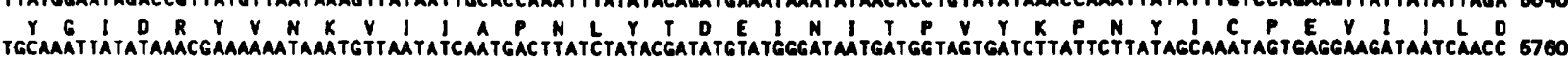




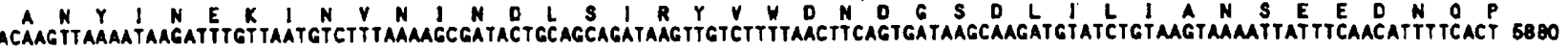

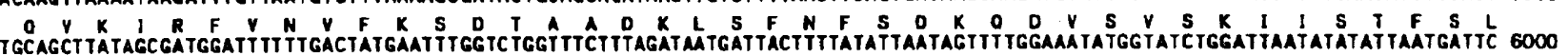
ATIATATTATTTCAAACCACCAAAAAATAACTTGATAACTGCATICACAACTATAGATGGTAATAAATATTACTTTGACCCAACGAAGAGTGGAGCTGCATCAATAGGAGAAATAACAAT 6120

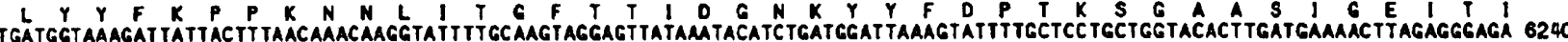

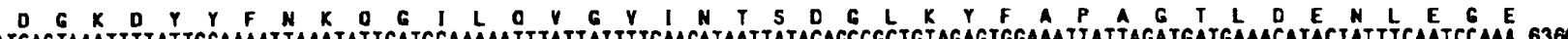

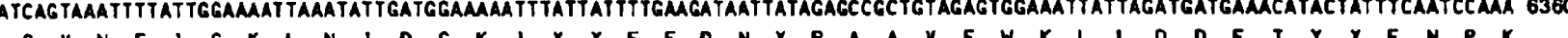

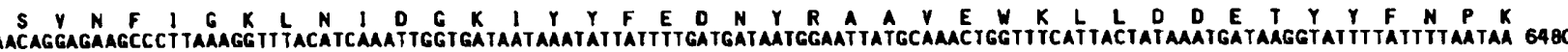

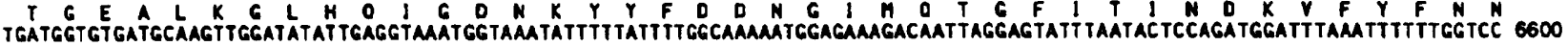

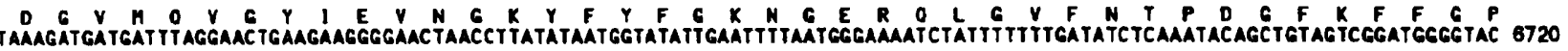

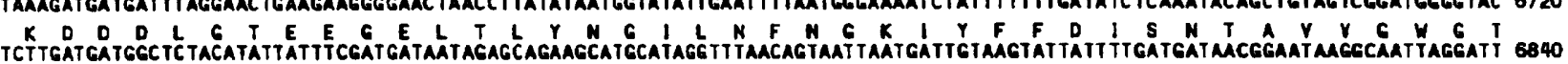

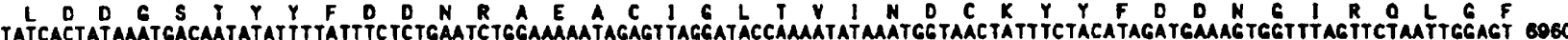

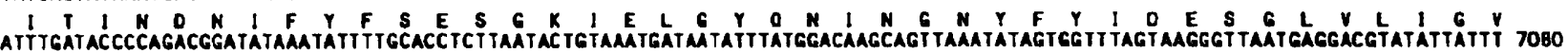
$F D T P D G Y K Y F A P L M T Y N D M Y Y G O A Y K Y S G L Y K Y M E D Y Y Y F$

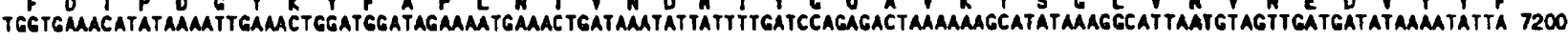

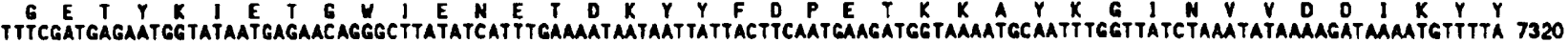

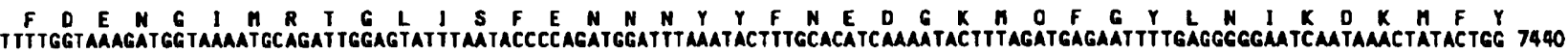

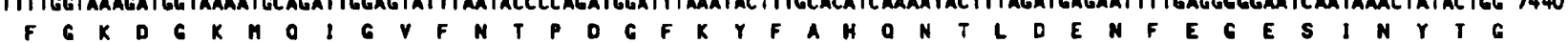

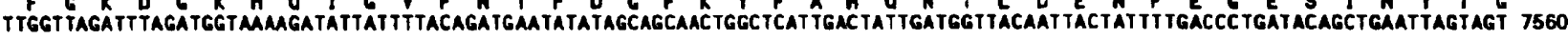

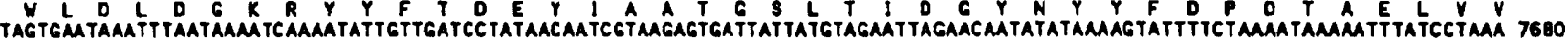

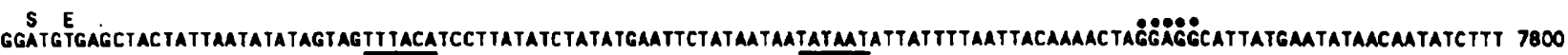

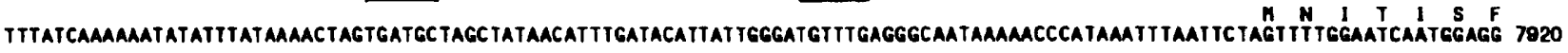

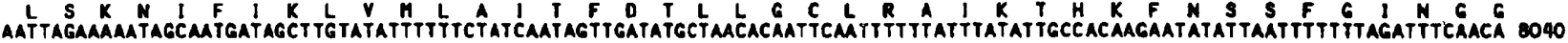

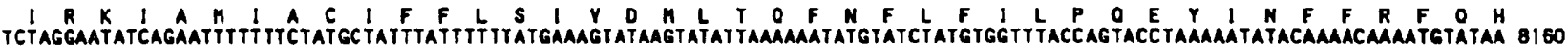

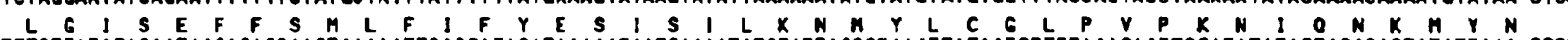

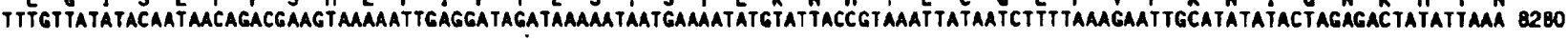

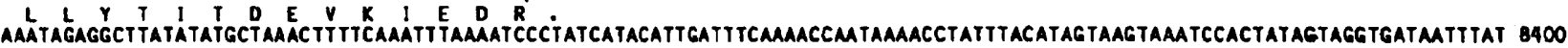

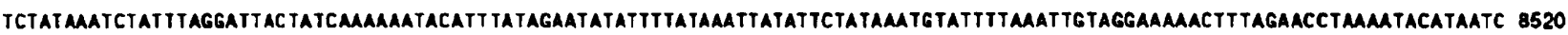

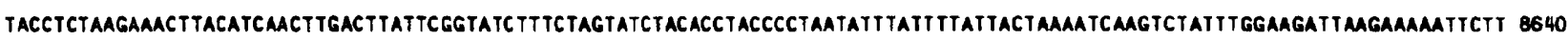

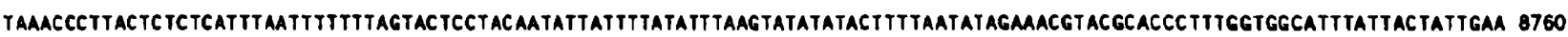

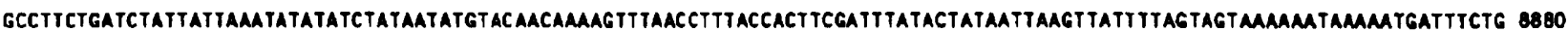

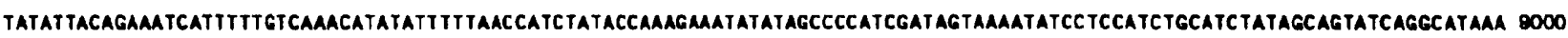

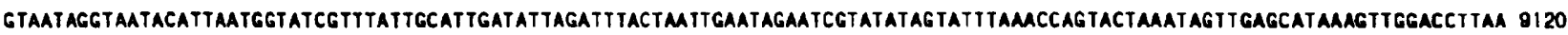

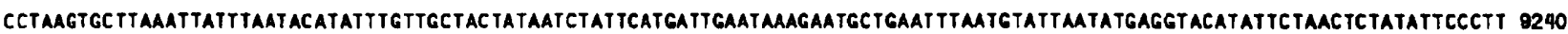

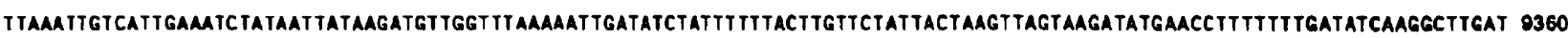

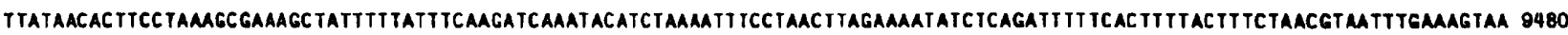

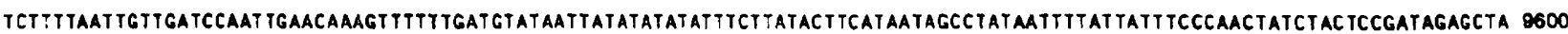
GGTCTAGA 9608

Fig. 1. Nucleotide sequence of a 9.6-kb fragment of $C$. sordellii genomic DNA containing the cytotoxin gene and a short ORF: putative ribosomal binding sites are indicated (O), putative ' -10 ' and ' -35 ' sequences are underlined.

(5'-GAAGCAGCTACTGGAT GGC-3' and 5'-AGCAGTGTTAGTATTAAA G-3'), were used to amplify the C. sordellii enterotoxin gene.

\section{Cloning and sequence analysis}

All cloning techniques employed were as described by Sambrook et al. [21]. An oligonucleotide probe $\left(5^{\prime}\right.$ GATGATATAAAATATTATTTTGAT 3', termed 'oligo rep') corresponding to a repetitive region at the 3 ' end of $C$. difficile cytotoxin was used as a probe to clone a 3.4-kb HindIII/EcoRI fragment of $C$. sordellii genomic DNA. Oligonucleotides corresponding to the $5^{\prime}$ and $3^{\prime}$ ends of this fragment were used to clone overlapping fragments. Two successive oligonucleotide probes were necessary at the $5^{\prime}$ end in order to cover the entire $C$. sordellii cytotoxin gene and its flanking regions, $9.6 \mathrm{~kb}$ in all. Fragments were cloned in pUC18 or pCRII and were subcloned into M13 mp130 or mp131 for sequencing. The $E$. coli host used was TG1 for pUC and M13 cloning, whereas $E$. coli strain inv $\alpha$ $F^{\prime}$ was used with pCRII. Sequencing was performed with the Pharmacia T7 sequencing kit. All restriction sites used for subcloning were sequenced across. Sequence data were analysed with DNAStar Software (DNAStar Ltd, London) for the Macintosh Computer. 
Table 1. Characteristics of $C$. difficile $68750, C$. sordellii VPI 9048 and C. sordellii 6018

\begin{tabular}{lccc}
\hline & $\begin{array}{c}\text { Culture } \\
\text { supernate } \\
\text { Bacterial strain }\end{array}$ & $\begin{array}{c}\text { Enterotoxicity } \\
\text { (ileal loop assay) }\end{array}$ & $\begin{array}{c}\text { ELISA for } \\
\text { C. difficile } \\
\text { enterotoxin }\end{array}$ \\
\hline C. difficile 68750 & + & + & + \\
C. sordellii VPI 9048 & + & + & + \\
C. sordellii 6018 & + & - & - \\
\hline
\end{tabular}

\section{Results}

The nucleotide sequence obtained for a 9.6-kb fragment of $C$. sordellii genomic DNA is presented in Fig. 1. The first long ORF corresponds to the cytotoxin and the second short ORF is unidentified. C. sordellii cytotoxin shows high homology with $C$. difficile cytotoxin $(76 \%$ identity, $90 \%$ similarity), and the short ORF shows $73 \%$ identity and $93 \%$ similarity with its $C$. difficile counterpart.

No enterotoxin activity was found in C. sordellii 6018 culture supernates in the rabbit ileal-loop assay (Table 1 ), whereas enterotoxin activity was detected for $C$. difficile 68750 and C. sordellii VPI 9048.

C. difficile and $C$. sordellii enterotoxins are also cytotoxic, but to a lesser degree than the cytotoxins [7]. Culture supernates for $C$. difficile 68750 were cytotoxin-positive and two peaks of cytotoxicity were obtained in anion-exchange chromatography eluting between 0.13 and $0.32 \mathrm{M} \mathrm{NaCl}$ (enterotoxin) and at $0.5-0.6 \mathrm{M} \mathrm{NaCl}$ (cytotoxin). C. sordellii VPI 9048 gave similar results $(0.22 \mathrm{M} \mathrm{NaCl}$, enterotoxin and $0.38-0.51 \mathrm{M} \mathrm{NaCl}$, cytotoxin). C. sordellii 6018 yielded a single peak eluting at $0.38-0.43 \mathrm{M} \mathrm{NaCl}$, corresponding to the cytotoxin.

Culture supernates of $C$. difficile 68750 and $C$. sordellii VPI 9048 gave positive results in the enterotoxin assay, as did the fractions corresponding to the first cytotoxic peak eluted in anion-exchange chromatography. In contrast, $C$. sordellii 6018 culture supernate and anion-exchange fractions eluting between 0.1 and $0.3 \mathrm{M} \mathrm{NaCl}$ showed no detectable enterotoxin in ELISA.

PCR amplification for $C$. difficile 68750 resulted in multiple bands characteristic of the repetitive region of the enterotoxin gene [10]. Similarly, PCR amplification of $C$. sordellii VPI 9048 DNA resulted in a multiple band pattern, distinguishable from that for $C$. difficile. In contrast, no amplification was found with these primers for DNA isolated from C. sordellii 6018 (Fig. 2).

\section{Discussion}

In $C$. difficile the cytotoxin gene is separated from a short ORF by $122 \mathrm{bp}$, which in turn is separated from the enterotoxin gene by $726 \mathrm{bp}$ [22]. Sequencing of the cytotoxin gene from $C$. sordellii 6018 showed a short ORF 210 nucleotides downstream. However, sequences for the next 1400 nucleotides downstream did not reveal another ORF that could correspond to the $C$. sordellii enterotoxin gene (EMBL accession number, X82638). Furthermore, no sequence homology was found with the recently published $\mathrm{NH}_{2}$-terminal peptide sequence of the enterotoxin [7]. Therefore, $C$. sordellii 6018 might: (1) produce an active enterotoxin but the small ORF-enterotoxin gene intergenic region may be longer than for $C$. difficile; (2) possess an enterotoxin gene that is transcribed but the enterotoxin is inactive; (3) possess an enterotoxin gene that is not transcribed or (4) not possess an enterotoxin gene, i.e., the gene could be partially or completely absent. Rabbit ileal loop assay indicated that this strain does not produce an active enterotoxin. The ELISA assay for $C$. difficile toxin showed strong cross-reaction for the enterotoxin of $C$. sordellii VPI 9048, but no reaction with supernates or fractions from $C$. sordellii 6018 . Neither of these results eliminates the possibility that either an active enterotoxin is produced, but at levels lower than can be detected, or that an inactive, non-cross-reacting protein is produced. However, together with the DNA sequencing evidence, and the failure to detect amplification with the $C$. difficile enterotoxin primers, the results strongly indicate that this strain contains a large deletion covering most, if not all, of the enterotoxin gene.

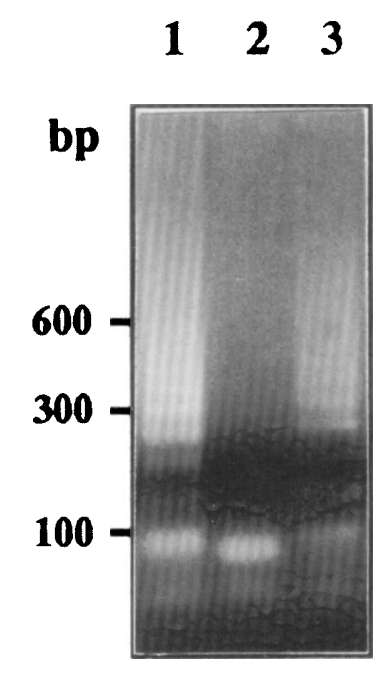

Fig. 2. PCR amplification of Clostridium DNA: 1, C. difficile $68750 ; 2, C$. sordellii $6018 ; 3, C$. sordellii VPI 9048. 
We thank J. M. Scheftel for performing the rabbit ileal-loop enterotoxicity test.

\section{References}

1. MacLennan JD. The histotoxic clostridial infections of man. Bact Rev 1962; 26: 177-276.

2. Arseculeratne SN, Panabokké RG, Wijesundera S. The toxins responsible for the lesions of Clostridium sordellii gas gangrene. J Med Microbiol 1969; 2: 37-53.

3. Hatheway CL. Toxigenic clostridia. Clin Microbiol Rev 1990; 3: 66-98.

4. Baldacini O, Green GA, Girardot R, Rihn B, Monteil H. Fast purification of Clostridium sordellii cytotoxin. $J$ Chromatogr 1990; 528: 357-369.

5. Baldacini O, Girardot R, Green GA, Rihn B, Monteil H. Comparative study of immunological properties and cytotoxic effects of Clostridium difficile toxin B and Clostridium sordellii toxin L. Toxicon 1992; 30: 129-140.

6. Popoff MR. Purification and characterization of Clostridium sordellii lethal toxin and cross-reactivity with Clostridium difficile cytotoxin. Infect Immun 1987; 55: 35-43.

7. Martinez RD, Wilkins TD. Comparison of Clostridium sordellii toxins $\mathrm{HT}$ and LT with toxins $\mathrm{A}$ and $\mathrm{B}$ of $\mathrm{C}$. difficile. $J \mathrm{Med}$ Microbiol 1992; 36: 30-36.

8. Fluit AC, Wolfhagen MJHM, Verdonk GPHT, Jansze M, Torensma R, Verhoef J. Nontoxigenic strains of Clostridium difficile lack the genes for both toxin A and toxin B. J Clin Microbiol 1991; 29: 2666-2667.

9. Kato $\mathrm{N}, \mathrm{Ou} \mathrm{CY}$, Kato $\mathrm{H}$ et al. Identification of toxigenic Clostridium difficile by the polymerase chain reaction. $J$ Clin Microbiol 1991; 29: 33-37.

10. Wren BW, Heard SR, al-Saleh AI, Tabaqchali S. Characterisation of Clostridium difficile strains by polymerase chain reaction with toxin A- and B-specific primers. $J$ Med Microbiol 1993; 38: 109-113.
11. Green GA, Riot B, Monteil $\mathrm{H}$. Identification of toxigenic Clostridium difficile strains using a toxin B gene-specific oligonucleotide probe. Mol Cell Probes 1992; 6: 101-105.

12. Borriello SP, Wren BW, Hyde S et al. Molecular, immunological, and biological characterization of a toxin A-negative, toxin B-positive strain of Clostridium difficile. Infect Immun 1992; 60: 4192-4199.

13. Torres JF. Purification and characterisation of toxin B from a strain of Clostridium difficile that does not produce toxin A. $J$ Med Microbiol 1991; 35: 40-44.

14. Lyerly DM, Barroso LA, Wilkins TD, Depitre C, Corthier G. Characterization of a toxin A-negative, toxin B-positive strain of Clostridium difficile. Infect Immun 1992; 60: 4633-4639.

15. Depitre C, Delmée M, Avesani V et al. Serogroup F strains of Clostridium difficile produce toxin B but not toxin A. $J$ Med Microbiol 1993; 38: 434-441.

16. Schué V, Green GA, Girardot R, Monteil H. Clostridium sordelli cytotoxin induces phosphorylation of an $80000 \mathrm{~mol}$. wt protein in McCoy cells. Toxicon 1994; 32: 1581-1592.

17. Green GA, Schué V, Monteil $\mathrm{H}$. Cloning and characterization of the cytotoxin L-encoding gene of Clostridium sordellii: homology with Clostridium difficile cytotoxin B. Gene 1995; 161: $57-61$.

18. Pierce NF, Wallace CK. Stimulation of jejunal secretion by a crude Escherichia coli enterotoxin. Gastroenterology 1972; 63: 439-448.

19. Schué V, Green GA, Monteil H. Comparison of the ToxA test with cytotoxicity assay and culture for the detection of Clostridium difficile-associated diarrhoeal disease. J Med Microbiol 1994; 41: 316-318.

20. Wren BW, Tabaqchali S. Restriction endonuclease DNA analysis of Clostridium difficile. J Clin Microbiol 1987; 25: 2402-2404.

21. Sambrook J, Fritsch EF, Maniatis F. Molecular cloning: a laboratory manual, 2nd edn. Cold Spring Harbor, NY, Cold Spring Harbor Laboratory Press. 1989.

22. Dove $\mathrm{CH}$, Wang S-Z, Price SB et al. Molecular characterization of the Clostridium difficile toxin A gene. Infect Immun 1990; 58: $480-488$. 